\title{
An Interesting Case of Thoracic Dermal Sinus
}

\section{Sunil Munakomi*}

Department of Neurosurgery, College of Medical Sciences, Chitwan, Nepal, India

\section{Description}

11 years old girl presented with history of on and off discharge from her upper back since childhood. Examination revealed presence of dermal sinus on her back (Figure 1). Neurological examination was normal. MRI revealed presence of track going upwards to the cervical region with presence of syrinx (Figures 2 and 3) and diastematomyelia (Figure 4).

Dermal sinus results from a failure of neuroectoderm to separate from the cutaneous ectoderm [1]. Thoracic and cervical regions where the neural folds fuse first are the rare sites for dorsal dermal sinus [2]. It is invariably associated with presence of dermoid and epidermoid tumors, tethered cord or defects of the posterior arches of the vertebral column. Common mode of presentation is frequent bouts of unexplained meningitis [3].

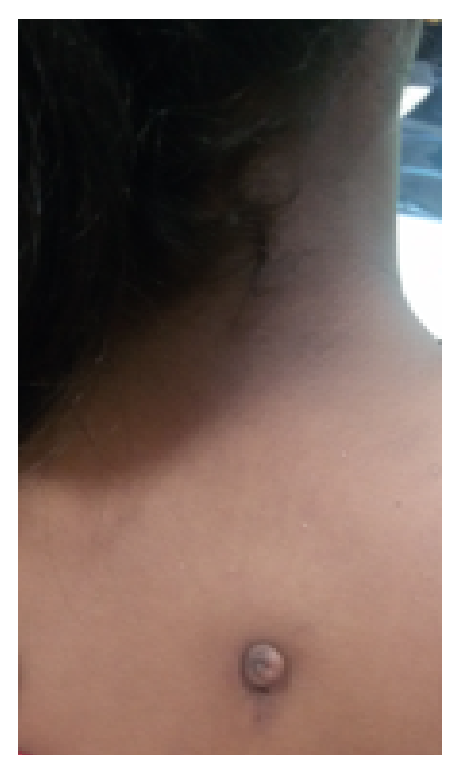

Figure 1: Presence of dermal sinus.

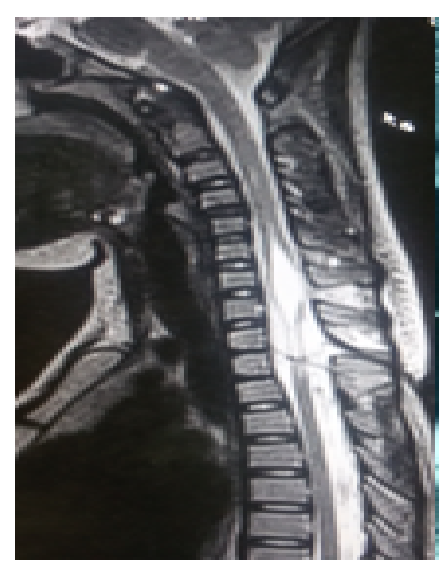

Figure 2: Presence of track towards the cervical region.

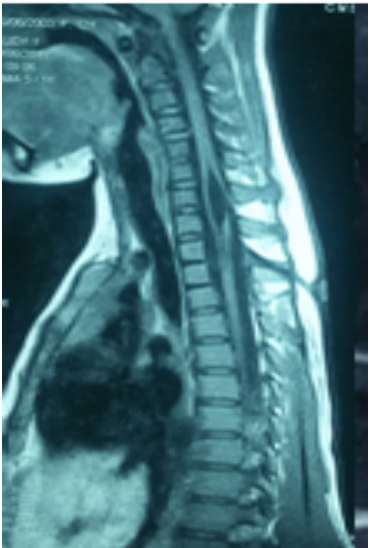

Figure 3: Presence of track towards the cervical region with Syrinx.

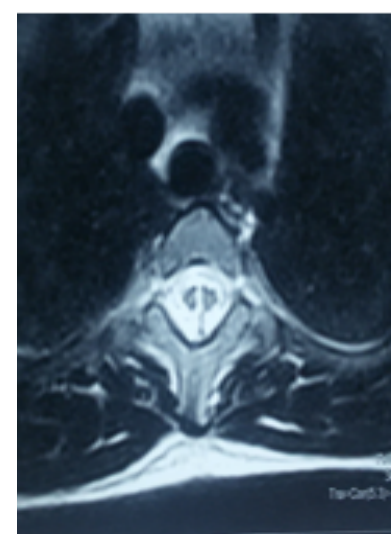

Figure 4: Diastematomyelia.

\section{References}

1. Wang KC, Yang HJ, Oh CW, Kim HJ, Cho BK (1993) Spinal congenital dermal sinus- experience of 5 cases over a period of 10 years. J Korean Med Sci 8: 341-347.

2. Mishra SS, Panigrahi S (2014) Thoracic congenital dermal sinus associated with intramedullary spinal dermoid cyst. J Pediatr Neurosci 9(1): 30-32.

3. Morandi X, Mercier P, Fournier HD, Brassier G (1999) Dermal sinus and intramedullary spinal cord abscess. Report of two cases and review of the literature. Childs Nerv Syst 15: 202-208.

*Corresponding author: Sunil Munakomi, Department of Neurosurgery, College of medical sciences, Chitwan, Nepal, India, Tel: +977 56-524203; E-mail: sunilmunakomi@gmail.com

Received November 18, 2015; Accepted November 20, 2015; Published November 23, 2015

Citation: Munakomi S (2015) An Interesting Case of Thoracic Dermal Sinus. J Neurol Disord 4: i102. doi:10.4172/2329-6895.1000i102

Copyright: (c) 2015 Munakomi S. This is an open-access article distributed under the terms of the Creative Commons Attribution License, which permits unrestricted use, distribution, and reproduction in any medium, provided the original author and source are credited. 